\title{
Risk Factors for Development of Keratoconus: A Matched Pair Case-Control Study
}

\author{
Loay Abdulmutalib Almusawi ${ }^{\prime}$ \\ Furkaan Majied Hamied ${ }^{2}$ \\ 'Department of Surgery, College of \\ Medicine, University of Basrah, Basrah, \\ Iraq; ${ }^{2}$ Department of Surgery, College of \\ Medicine, University of Al-Qadisiyah, Al \\ Diwaniyah, Iraq
}

Background: Keratoconus, a progressive ectatic corneal disorder, is believed to be multifactorial in etiology with interaction between genetic and environmental factors. To date, risk factors for the development of the disease are extensively debated and need to be identified since they play a critical role in disease prevention and management. This study aimed to analyze associations between several hereditary and environmental predictors and the development of keratoconus.

Patients and Methods: This was a retrospective matched pair case-control study. The study was conducted in Ibn-Alhaitham eye teaching hospital between March 2016 and April 2017. Patients with keratoconus (cases) and their age- and gender-matched controls were asked about childhood and early teenage eye rubbing, ocular trauma, obesity, contact lens wear, smoking and sunlight exposure, family history of keratoconus, parental consanguinity and information related to socio-economic status. Univariable and multivariable conditional logistic regression analyses were used to test the significance of associations.

Results: A total of 166 individuals (83 cases and 83 controls; $60.2 \%$ female) were included. On univariable analysis, eye rubbing, family history of keratoconus and parental consanguinity were significant risk factors for keratoconus, whereas all other factors were non-significant. On multivariable analysis, eye rubbing (odds ratio: $4.93 ; P<0.01$ ), family history of keratoconus (odds ratio: 25.52; $P<0.01$ ) and parental consanguinity (odds ratio: 2.89; $P=0.02$ ), again, emerged as significant risk factors for disease development.

Conclusion: Family history of keratoconus, eye rubbing, and parental consanguinity were significant risk factors for keratoconus development. These results support the evidence for multifactorial etiology, the most important factor being hereditary predisposition.

Keywords: keratoconus, corneal ectasia, childhood eye rubbing, parental consanguinity

\section{Plain Language Summary}

The human cornea, the transparent foremost part of the eye, can be affected by a variety of diseases, one of which is keratoconus. In this potentially blinding condition, the patient will suffer from impairment of vision and distortion of the images. It happens because the cornea becomes progressively weaker and protrudes in a cone-like shape, as the name implies, instead of being regularly convex on its front surface. This in turn causes irregular astigmatism, usually myopic, which in many cases cannot be corrected with glasses or soft contact lenses and will require surgical procedures to halt progression of the disease and rehabilitate patient vision. They can include corneal transplant surgery for the advanced cases. Some risk factors for this disease are clearly demonstrated in literature such as childhood eye rubbing and positive family history of the disease, others are still debated. In this study, we examined several different presumed risk factors, and it has been found that besides childhood eye rubbing and family history which increase its risk by four and 25 times respectively in our
Correspondence: Loay Abdulmutalib Almusawi

Email loay.almusawi@uobasrah.edu.iq 
study, parental consanguinity is also a risk factor for the disease, increasing its risk to almost three times. This could mean that in those families that have patients of keratoconus, the risk of the disease will be much heightened in their children if their members are married to relatives up to a second cousin relationship. Public education regarding early treatment of allergic eye conditions and refraining from eye rubbing could also prevent new cases of the disease.

\section{Introduction}

Keratoconus is a corneal ectatic disorder characterized by cone-like protrusion of the cornea with significant visual impairment. The disorder is typically bilateral and progressive. ${ }^{1}$ The main clinical effects are reduced visual acuity, distortion of images with abnormally high sensitivity to light and glare. ${ }^{2}$ This condition is characterized by difficult refractive correction using spherocylindrical spectacle lenses due to irregular astigmatism secondary to corneal asymmetry. ${ }^{3}$ The clinical onset of the disease is often at puberty and it remains progressive throughout the 2nd and 3rd decades of life; however, progression has been documented even after 30 years of age. ${ }^{4}$ The clinical manifestation and disease progression are highly variable between patients. It is also frequently asymmetric between eyes in the same patient, and even cases of unilateral keratoconus have been reported. 5,6

The etiology of the disease remains enigmatic; however, it is postulated that repeated trauma in genetically predisposed individuals is the most likely explanation. ${ }^{6,7}$ The disease may be associated with chronic eye rubbing, rigid gas-permeable contact lens wear, atopy and systemic conditions such as Down syndrome, Leber's congenital amaurosis, and connective tissue disorders. ${ }^{8}$ It is viewed as a hereditary condition since positive family history is reported in $6 \%$ to $8 \%$ of cases, while environmental factors also play a role in disease progression. ${ }^{6,9,10}$

The prevalence of the disease in the general population varies considerably among different regions of the world from as low as $0.0003 \%$ in Russia to as high as $5.3 \%$ in male Arab students in Israel. ${ }^{11,12}$ With one large study in Netherlands reporting a prevalence of $1: 375(0.27 \%){ }^{13}$ and more recently a relatively high prevalence $(1.2 \%)$ is reported in an Australian population based on scheimpflug imaging. ${ }^{14}$ This variation could be attributed to ethnic differences, endogamy rate, improvement in diagnostics or lack of standardized criteria for diagnosis. ${ }^{15}$ From the pathophysiological perspective, it is agreed that the disease has no primary explanation and is likely to include environmental, biomechanical, genetic, and biochemical disorders. ${ }^{16}$ Corneal pachymetry, tomography and topography are the principal diagnostic tools used to establish keratoconus diagnosis. $^{17}$

The disease can have a significant impact on quality of life $^{18}$ and treatment modalities to halt its progression (such as corneal collagen cross-linking) or to improve vision (such as specially designed contact lenses, intra-corneal ring implantation or keratoplasty), although have shown good result, but are not free of risks and financial burdens. 2,16,19 Patient education about the risk factors for this disease may aid in its prevention thereby reducing its overall impact.

The rationale for the current study was a lack of consensus on the exact causes and risk factors of the disease. The study aimed to identify possible risk factors associated with the disease in a sample of Iraqi patients with a diagnosis of keratoconus.

\section{Patients and Methods}

This retrospective matched pair case-control study was conducted during the period from May 2016 to April 2017 at the Ibn-Alhaitham teaching eye hospital, Baghdad (Iraq). Cases of keratoconus (KC) were diagnosed based on both clinical and tomographic findings in accordance with the global consensus of $\mathrm{KC}$ and ectatic diseases definition. ${ }^{16}$ To maximize the sample size and range, all keratoconic patients attending the hospital during this period were eligible. Reasons for attendance included first diagnosis, follow-up, admission for cross linking procedure, referral to keratoplasty committee unit, and minor operations unit. Inclusion criteria for controls were: (1) absence of clinical and, when required, tomographic evidence for keratoconus, (2) normal anterior and posterior segment examination of the eye, (3) willingness to participate in the study. Controls were individuals accompanying patients attending to the same hospital for reasons other than keratoconus, companions of patients of keratoconus were labeled controls only after assuring they are not their own relatives. We also included in the control group some hospital staff and friends and relatives of the researchers. Controls and cases were ageand gender-matched in a ratio of 1:1 and each control was selected so that its age is within two years of that of its matched case. Exclusion criteria for both cases and controls include at least one of: (1) inability to accurately recall events related to questionnaire of the study, (2) mental retardation, (3) presence of severe ocular surface 
disease or corneal pathology that might interfere with accurate diagnosis of $\mathrm{KC}$. For each $\mathrm{KC}$ patient (case) and control participant, a formal ocular examination was undertaken, including: both objective and subjective refraction, uncorrected and best-corrected distance visual acuity, slit-lamp anterior segment examination and fundoscopy. All cases and most controls had undergone corneal tomographic examination using the Pentacam (Oculus Inc, Wetzlar, Germany).

The study was approved by the institutional ethics committee at scientific department of Ibn-Alhaitham eye teaching hospital and it followed the principles of Declaration of Helsinki. All patients and controls were informed about the purpose of the study. After verbal informed consent for participation, which was approved by the institutional ethics committee of the respective hospital, both cases and controls were interviewed by the researchers to complete the same questionnaire (Figure 1) on demographics and risk factors, including details of their age, gender, occupation, education, exposure to sunlight, previous contact lens use, history of significant ocular trauma ("significant" defined as prompting medical attention), history of frequent eye rubbing, history of childhood and early teenage obesity, family history of keratoconus, parental consanguinity and smoking history. Sunlight exposure behavior during teenage years was evaluated based on the average number of daylight hours spent outdoors daily whether recreational or occupational. Parental consanguinity was defined as any biological relation between parents closer than second cousins. Data were initially collected as paper-based questionnaire forms.

On disease-related questions, the questionnaire differed between cases and controls, with questions for cases including the age at which progressive blurring of vision first occurred or the age at diagnosis, whichever was earlier, and the use of contact lenses prior to diagnosis.

Socio-economic status (SES) was assessed according to educational level, parental occupation and locality (urban vs rural). Individuals were categorized as positive for smoking history if they were exposed to passive or active smoking and negative if exposed to neither. The items in the questionnaire relating to eye rubbing, sunlight exposure rate, obesity, contact lens use, smoking exposure, and ocular trauma were specific to childhood and teenage years (prior to the development of the disease in cases) because this is considered a critical period for the pathogenesis of keratoconus. The questionnaire also highlighted the systemic diseases known to be associated with $\mathrm{KC}$ such as Down syndrome, connective tissue diseases (Marfan and Ehlers-Danlos syndromes) and Leber congenital amaurosis. ${ }^{16}$

Statistical analysis was performed using SPSS version 23. Variables were expressed as number, percentage, mean and standard deviation. An independent samples $t$-test or Mann Whitney $U$-test were used to compare indices of central tendency, as appropriate, according to fulfillment of statistical assumptions. As each case was individually age- and gender-matched to a suitable control, crude odds ratio (OR) and 95\% confidence interval (CI) of the OR for univariable analysis were calculated using the McNemar test. Subsequently, to control for the effect of other predictors, data that were significant on univariable analysis were subsequently subjected to multivariable conditional binomial logistic regression analysis (utilizing the COXREG function of the survival package in SPSS), to calculate the adjusted OR. The level of significance was set at $P \leq 0.05$.

\section{Results}

Records from 33 males and 50 females (female to male ratio 1.52:1) were included. The mean age of patients was $22.58 \pm 6.5$ years and that of control subjects was 22.60 \pm 6.66 years. No significant difference was found between the groups in age or gender frequency distribution $(P>0.05)$.

The prevalence rate of possible risk factors in patients and controls is shown in Table 1. No participant had any systemic disease known to be associated with $\mathrm{KC}$ such as Down syndrome, Marfan syndrome, Ehlers-Danlos and other systemic connective diseases. Table 2 shows, for each risk factor, the number of patient and control matched pairs in which either the patient or the control was exposed to the factor, and the results of univariable and multivariable analysis. Eye rubbing, positive family history and parent consanguinity were the main risk factors with adjusted odd ratios of 4.93, 25.52 and 2.89 , respectively.

\section{Discussion}

The objective of the study was to estimate the prevalence of well-established risk factors for keratoconus (family history and eye rubbing, certain ocular and systemic diseases) ${ }^{16}$ among patients attending Ibn-Alhaitham teaching eye hospital, Baghdad (Iraq) and to assess the role of a range of putative (risk/protective) factors. These included parental consanguinity, low SES, obesity, ocular trauma, pre-diagnosis contact lens wear, and exposure to 
Participant ID:

Case

control

Date of birth:

Gender:

For cases, what was the age of diagnosis or onset of symptoms of keratoconus?

Do you rub your eyes frequently during childhood and teenage years?

$\square$ Yes $\quad \square$ No

Do you have a member in your family with a diagnosis of keratoconus?

$\square$ Yes $\quad \square$ No

Are your parents relatives? If yes, what is the kinship degree?

$\square$ Yes $\quad \square$ No

Kinship

Do you have history of ocular trauma prompting medical attention? If yes when did that happen?

$\square$ Yes $\quad \square$ No

Date of incident

Did you wear a contact lenses before? how frequent? Why did you wear them?

$\square$ Yes $\quad \square$ No

Frequency___ Reason(s)_

Do you have a history of childhood obesity?

$\square$ Yes $\quad \square$ No

How many hours per day, on average, had you spent outdoor in daylight when you were a child and teenage?

$\square 4$ or more hours $\quad \square$ less than 4 hours per day

Were you exposed to active or passive smoking previously? If yes when was that?

$\square$ Yes

$\square$ No

Notes (duration and when?)

In which neighborhood do you live?

Have you completed more than 12 years of education? What is your current education? And occupation?

$\square$ Yes $\quad \square$ No

Education Occupation(s)

Had your parents completed more than 12 years of education?

$\square$ Yes

$\square$ No

What are/were your parents occupations? And educational level?

Father Mother

Had you had to work as a child to earn living?

$\square$ Yes $\quad \square$ No

Do you have any systemic disease such as connective tissue diseases (Marfan and Ehher-Danlos syndromes), Down and Leber congenital amaurosis? If yes specify?

$\square$ Yes $\quad \square$ No

Figure I Translated questionnaire form. 
Table I The Prevalence Rate of Possible Risk Factors in Patients and Control Groups

\begin{tabular}{|l|c|c|c|c|}
\hline \multirow{2}{*}{ Risk Factor } & \multicolumn{2}{|c|}{ Patients n = 83 } & \multicolumn{2}{c|}{ Control n = 83 } \\
\cline { 2 - 5 } & $\mathbf{n}$ & $\%$ & $\mathbf{n}$ & $\%$ \\
\hline Eye rubbing & 47 & 56.6 & 19 & 22.9 \\
Eye trauma & 8 & 9.6 & 4 & 4.8 \\
Positive family history & 19 & 22.9 & 2 & 2.4 \\
Parent consanguinity & 60 & 72.3 & 33 & 39.8 \\
Contact lens use & 6 & 7.2 & 8 & 9.6 \\
Obesity & 19 & 22.9 & 12 & 14.5 \\
Smoking & 30 & 36.1 & 29 & 34.9 \\
Sunlight $\geq 4$ hours per day & 18 & 21.7 & 25 & 30.1 \\
Low socioeconomic status & 27 & 32.5 & 34 & 41.0 \\
\hline
\end{tabular}

sunlight and to smoking. These factors are still debated so the overall aim was to deepen understanding of the disease etiology.

In our study, childhood eye rubbing was a significant risk factor for $\mathrm{KC}$ development on both univariable and multivariable analyses. Case-control studies provide the most compelling evidence of the association between eye rubbing and $\mathrm{KC},{ }^{20}$ and one such study conducted in the Middle East by Gordon-Shaag et al showed that $63 \%$ of patients with $\mathrm{KC}$ had a history of eye rubbing with an adjusted OR of (3.37). ${ }^{21}$ Numerous other authors have described this significant association, while in some studies the data did not reach statistical significance. This discrepancy in results may stem from environmental differences, such as high levels of dust in some climates leading to a higher prevalence of eye rubbing among patients and controls, thus concealing a possible association. The association is not necessarily causative, since many patients did not have a history of eye rubbing. It has been suggested that epithelial microtrauma from rubbing results in cytokines release and keratocytes apoptosis. ${ }^{20}$

It is of particular interest that three cases in our sample were derived from the same family (two brothers and one sister), with only one male having a history of childhood eye rubbing so several other factors might come into play. For example, using logistic regression analysis, Bawazeer et al concluded that $\mathrm{KC}$ was not associated with atopy, but with eye rubbing so that atopy may be indirectly associated with $\mathrm{KC}$ due to the itching that it induces. ${ }^{20,22}$

It is widely accepted that a family history of $\mathrm{KC}$ is strongly associated with diagnosis of the disease, and in our study, we found that positive family history was present in 19 cases $(22.9 \%)$, whilst only two controls $(2.4 \%)$ demonstrated a positive family history of KC. Similar prevalence of positive family history has been reported by Gordon-Shaag et al in 2013 in Jerusalem. ${ }^{23}$ Other studies have reported variable prevalence ranging from $(0 \%)$ to $(26 \%) .^{12,20-23}$ Possible explanations for this variation include the range of methods used to determine whether a family member is considered positive for the disease, variations in the definition of a family, or racial differences. It is worth noting that a positive family history may reflect both genetic and environmental influences. It is relevant to genetic influence that we found a strong association between parental consanguinity and the diagnosis of $\mathrm{KC}$ independent from all other significant risk factors, with $72 \%$ of cases but only $40 \%$ of controls reporting a positive history for parental consanguinity.

Table 2 The Risk Related to Each Factor, Determined from Univariable and Multivariable Analyses

\begin{tabular}{|c|c|c|c|c|c|c|c|c|}
\hline \multirow[t]{2}{*}{ Risk Factors } & \multirow{2}{*}{$\begin{array}{l}\text { Number of } \\
\text { Pairs with } \\
\text { Only Cases } \\
\text { Exposed }\end{array}$} & \multirow{2}{*}{$\begin{array}{l}\text { Number of } \\
\text { Pairs with Only } \\
\text { Controls } \\
\text { Exposed }\end{array}$} & \multicolumn{3}{|c|}{ Univariable Analysis } & \multicolumn{3}{|c|}{ Multivariable Analysis } \\
\hline & & & $P$ value & $\begin{array}{c}\text { Crude } \\
\text { OR }\end{array}$ & $95 \% \mathrm{Cl}$ & $P$ value & $\begin{array}{l}\text { Adjusted } \\
\text { OR }\end{array}$ & $95 \% \mathrm{Cl}$ \\
\hline Eye rubbing & 37 & 9 & $<0.001$ & 4.11 & $1.94-9.68$ & 0.002 & 4.93 & $1.82-13.34$ \\
\hline Positive family history & 19 & 2 & $<0.001$ & 9.50 & $2.29-8.11$ & 0.006 & 25.52 & $2.56-254.36$ \\
\hline Parent consanguinity & 36 & 9 & $<0.001$ & 4.00 & $1.89-9.44$ & 0.02 & 2.89 & $1.16-7.16$ \\
\hline Trauma & 7 & 3 & 0.343 & 2.33 & $0.53-13.98$ & & & \\
\hline Contact lens use & 3 & 5 & 0.724 & 0.60 & $0.09-3.08$ & & & \\
\hline Obesity & 17 & 10 & 0.284 & 1.70 & $0.73-4.15$ & & & \\
\hline Smoking & 21 & 20 & 1.000 & 1.05 & $0.54-2.04$ & & & \\
\hline Sunlight $\geq 4$ hours per day & 14 & 21 & 0.311 & 0.66 & $0.31-1.37$ & & & \\
\hline $\begin{array}{l}\text { Low socioeconomic } \\
\text { status }\end{array}$ & 15 & 22 & 0.342 & 0.68 & $0.32-1.37$ & & & \\
\hline
\end{tabular}

Abbreviations: $\mathrm{OR}$, odds ratio; $\mathrm{Cl}$, confidence interval. 
To the best of our knowledge, this is the second casecontrol study in the Middle East to have reported this association. However, in the corresponding study ${ }^{23}$ significant association was with consanguinity including first but not second cousins, while in the present study only total parental consanguinity (both first- and secondcousins) was analyzed and found to be significantly associated with KC. Shneor et al in Haifa (2014), in a prevalence study involving 314 college students, found that offspring of consanguineous marriage had a fivefold risk of having $\mathrm{KC}$; however, only parental first cousin consanguinity was found to be significant. ${ }^{12}$ Twin studies provide another source of striking evidence for genetics. In a United Kingdom-based study on 18 pairs of twins, Tuft et al concluded that $\mathrm{KC}$ was more concordant among monozygotic than dizygotic twins. ${ }^{24}$ However, none of the cases in the present study sample was a twin.

In the current study, although low SES was more prevalent among controls, this difference was not statistically significant and univariable analysis showed no significant association with KC. While previous studies used parental education as an indicator of SES, since an association has been shown between the two, ${ }^{20}$ we used participants' educational level, address and income to derive information related to SES. Gordon-Shaag et al reported that parental education $>12$ years was protective against $\mathrm{KC}^{21}$ while an earlier study by the same group found that the individual's education of $>12$ years was significantly associated with $\mathrm{KC},{ }^{22}$ and accounted for the latter finding on the basis that educated persons are more likely to seek medical attention. The Central India Eye and Medical Study showed using multivariable analysis a significant association between $\mathrm{KC}$ and low educational level. ${ }^{25}$

The current study, in accordance with contemporary opinion, found that contact lens (CL) wear was not related to the etiology of KC. Most CL wear was infrequent and for purely cosmetic reasons. Although $\mathrm{CL}$ have been a cornerstone for the management of $\mathrm{KC},{ }^{20,22}$ few authors believe that CL wear is related to progression of the disease. Fodor et al in 2013 demonstrated that CL wear may influence the levels and dynamics of various mediators in the tears of $\mathrm{KC}$ patients and in this way might impact on disease progression. ${ }^{26}$

In the present study, controls reported a slightly but not significantly higher number of hours of childhood sunlight exposure. $\mathrm{KC}$ is known to be more common in areas with high sunlight exposure rate ${ }^{20}$ however, other factors may be involved and on the contrary excessive ultraviolet sunlight exposure might promote natural cross linking of corneal collagen, assumed to be protective against the disease. ${ }^{20}$ The lack of significance of our results may be related to this dual protective and damaging effect of UV light, or the exposure dose could be at a subthreshold level for any demonstrable effect. Likewise, other presumed predictors (ocular trauma, childhood obesity and exposure to smoking) were not associated with the risk of developing $\mathrm{KC}$ in our study, in agreement with the two casecontrol studies by Gordon-Shaag et al. ${ }^{21,23}$ Spoerl et al found a negative association between smoking and $\mathrm{KC}$, and hypothesized that toxic by-products might induce cross linking of the stromal corneal collagen. ${ }^{27}$ However, unlike our study they analyzed smoking after the development of the disease which might explain the difference in results. Limitations include the retrospective nature of the study and the lack of subgroup analysis regarding first and second cousin parental consanguinity.

In summary, our study confirms the notion that $\mathrm{KC}$ is multifactorial in etiology with predominance of factors related to heredity (family history and parental consanguinity). Eye rubbing was associated with a more than 4-fold increase in risk of $\mathrm{KC}$, while positive family history of $\mathrm{KC}$ and parental consanguinity resulted in approximately 25 fold and 3-fold increased risk of the disease, respectively. These results support the complex origin of the disease with hereditary component having greater influence and can form a base for public education and counselling of affected families. Of note, regarding previous knowledge, is the association with parental consanguinity. The authors recommend that childhood eye rubbing should be discouraged and managed early and intensively particularly for those with positive family history of keratoconus. Consanguineous marriage is also discouraged particularly among affected families.

\section{Abbreviations}

$\mathrm{KC}$, keratoconus; $\mathrm{CI}$, confidence interval; $\mathrm{CL}$, contact lens; OR, odds ratio; SES, socio-economic status; UV, ultraviolet.

\section{Acknowledgment}

We thank head of refractive surgery department at IbnAlhaitham eye teaching for his general support, and department staff for assisting us in performing the required clinical tests for this study. 


\section{Funding}

Funding was self-provided by authors.

\section{Disclosure}

The authors declare no competing interests in this work.

\section{References}

1. Sharif R, Bak-Nielsen S, Hjortdal J, Karamichos D. Pathogenesis of keratoconus: the intriguing therapeutic potential of prolactin-inducible protein. Prog Retin Eye Res. 2018;67:150-167. doi:10.1016/j.preteyeres.2018.05.002

2. Alhayek A, Lu PR. Corneal collagen crosslinking in keratoconus and other eye disease. Int J Ophthalmol. 2015;8(2):407-418.

3. Moschos MM, Nitoda E, Georgoudis P, Balidis M, Karageorgiadis E, Kozeis N. Contact lenses for keratoconus - current practice. Open Ophthalmol J. 2017;11:241-251.

4. Gokul A, Patel DV, Watters GA, et al. The natural history of corneal topographic progression of keratoconus after age 30 years in noncontact lens wearers. Br J Ophthalmol. 2017;101:839-844.

5. Ghassembaglou N, Djalilian AR. Keratoconus; a true corneal disease. J Ophthalmic Vis Res. 2016;11(1):1-2.

6. Rabinowitz YS, Galvis V, Tello A, Rueda D, García JD. Genetics vs chronic corneal mechanical trauma in the etiology of keratoconus. Exp Eye Res. 2021;202:108328.

7. Grieve K, Ghoubay D, Georgeon C, et al. Stromal striae: a new insight into corneal physiology and mechanics. Sci Rep. 2017;7 (1): 13584 .

8. Prasannakumary C, Valiyaveettil B, Padma BP, Jyothi PT. Comparison of topographic and biomicroscopic features among symptomatic keratoconic eyes. Digit J Ophthalmol. 2018;29:44-48.

9. Gokul A, Patel DV, McGhee CN. Dr John Nottingham's 1854 landmark treatise on conical cornea considered in the context of the current knowledge of keratoconus. Cornea. 2016;35(5):673-678.

10. Kanellopoulos AJ, Asimellis G. Forme fruste keratoconus imaging and validation via novel multi-spot reflection topography. Case Rep Ophthalmol. 2013;4(3):199-209.

11. Gorskova EN, Sevost'ianov EN. Epidemiology of keratoconus in the urals. Vestn Oftalmol. 1998;114:38-40.

12. Shneor E, Millodot M, Gordon-Shaag A, et al. Prevalence of keratoconus among young Arab students in Israel. Int $J$ Keratoconus Ectatic Corneal Dis. 2014;3(1):9-14.

13. Godefrooij DA, de Wit GA, Uiterwaal CS, Imhof SM, Wisse RPL. Age-specific incidence and prevalence of keratoconus: a nationwide registration study. Am J Ophthalmol. 2017;175:169-172.
14. Chan E, Chong EW, Lingham G, et al. Prevalence of keratoconus based on scheimpflug imaging. Ophthalmology. 2021;128 (4):515-521.

15. Asimellis G, Kaufman EJ. Keratoconus. In: StatPearls [Internet]. Treasure Island (FL): StatPearls Publishing; January, 2019.Available from https://www.ncbi.nlm.nih.gov/books/NBK470435/. Accessed August 6, 2021.

16. Gomes JA, Tan D, Rapuano CJ, et al. Global consensus on keratoconus and ectatic diseases. Cornea. 2015;34(4):359-369.

17. Huseynli S, Abdulaliyeva F. Evaluation of scheimpflug tomography parameters in subclinical keratoconus, clinical keratoconus and normal caucasian eyes. Turk J Ophthalmol. 2018;48(3):99-108.

18. Sahebjada S, Fenwick EK, Xie J, Snibson GR, Daniell MD, Baird PN. Impact of keratoconus in the better eye and the worse eye on vision-related quality of life. Invest Ophthalmol Vis Sci. 2014;55(1):412-416.

19. Ronald LR, Steven MK, Jeffrey JW, Mae OG. The lifetime economic burden of keratoconus: a decision analysis using a Markov model. Am J Ophthalmol. 2011;151(5):768-773.

20. Gordon-Shaag A, Millodot M, Shneor E, Liu Y. The genetic and environmental factors for keratoconus. BioMed Res Int. 2015;2015:1-19.

21. Gordon-Shaag A, Millodot M, Kaiserman I, et al. Risk factors for keratoconus in Israel: a case-control study. Ophthalmic Physiol Opt. 2015;35:673-681.

22. Bawazeer AM, Hodge WG, Lorimer B. Atopy and keratoconus: a multivariate analysis. Br J Ophthalmol. 2000;84(8):834-836.

23. Gordon-Shaag A, Millodot M, Essa M, Garth J, Ghara M, Shneor E. Is consanguinity a risk factor for keratoconus? Optom Vis Sci. 2013;90:448-454.

24. Tuft SJ, Hassan H, George S, Frazer DG, Willoughby CE, Liskova P. Keratoconus in 18 pairs of twins. Acta Ophthalmol. 2012;90(6): e282-6.

25. Jonas JB, Nangia V, Matin A, Kulkarni M, Bhojwani K. Prevalence and associations of keratoconus in rural Maharashtra in central India: the central India eye and medical study. Am $J$ Ophthalmol. 2009;148:760-765.

26. Fodor M, Kolozsvári BL, Petrovski G, et al. Effect of contact lens wear on the release of tear mediators in keratoconus. Eye Contact Lens. 2013;39:147-152.

27. Spoerl E, Raiskup-Wolf F, Kuhlisch E, Pillunat LE. Cigarette smoking is negatively associated with keratoconus. J Refract Surg. 2008;24(7):S737-40.
Clinical Ophthalmology

\section{Publish your work in this journal}

Clinical Ophthalmology is an international, peer-reviewed journal covering all subspecialties within ophthalmology. Key topics include: Optometry; Visual science; Pharmacology and drug therapy in eye diseases; Basic Sciences; Primary and Secondary eye care; Patient Safety and Quality of Care Improvements. This journal is indexed on PubMed

\section{Dovepress}

Central and CAS, and is the official journal of The Society of Clinical Ophthalmology (SCO). The manuscript management system is completely online and includes a very quick and fair peer-review system, which is all easy to use. Visit http://www.dovepress.com/ testimonials.php to read real quotes from published authors. 